\title{
(Re) Stitch Tampa - Designing the Design Competition: The Architectural Design Competition as a Research Platform and Pedagogical Tool
}

\author{
SHANNON BASSETT
}

Laurentian University

(Re) Stitch Tampa serves as a useful precedent that demonstrates the agency the design ideas competition can serve across many facets, including as a research platform, a pedagogical tool, as well as a platform for exploring new emerging methods and modes of architectural representation.

The brief was inspired from the proposed implementation of the initial high-speed rail line to be put in between Tampa and Orlando announced by the Obama Administration, earmarking 1.2 billion dollars of federal monies for its implementation. Due to partisan/Tea Party politics the project did not move forward.

The competition was initially premised as a critique of the failings of the post-war American City with the potential for architectural design to act as a catalyst for its recovery. It also called for resilient design strategies which addressed and responded to Tampa's coastal location, including the rearticulation of its land-water edge condition. It began with a call for "innovative design ideas, which employed connective urban landscapes and ecological infrastructure as an underlying urban design framework and that this urban framework might act as a catalyst for the economic redevelopment for Tampa, while physically reconnecting a currently disparate and fragmented city and community." ${ }^{11}$ It called for a critical re-thinking of the ebbs and flows of circulation and movement throughout the city, and how these might contribute to more sustainable development and ecological practices. Overarching to these themes was how this recalibration and choreography might better connect the city and its inhabitants to the River, a natural lifeline running through the city, not currently part of the city's experience.

The brief poses how this framework might begin to choreograph the flows and movements through the city to and from the River through urbanism and place making. An urban design masterplan, which was initially to be focussed around the expected high-speed rail station, was modified to the charge of re-thinking how the infrastructure might connect the city back to its River. Implicit in this was also the phenomenological experience of the city. ${ }^{2}$

Open-ended frameworks included conceptualizing possible spatial configurations which might occupy the rights of way along the River, which is to become the primary organizing spine for the city. Proposals appropriated interstitial spaces of the city found under highway infrastructure, in reclaimed vacant lots and in surface parking lots as well as foreclosed properties.

Ecological processes were integrated into the schemes, processes which included storm water mitigation, resiliency to sea level rise, as well as shoreline and habitat restoration. Schemes prompted a critical re-thinking of the current oppositional relationship of the city to its water, as well as the potential to re-stitch, re-cover and re-claim the landscape of the post-war coastal American city through ecologies.

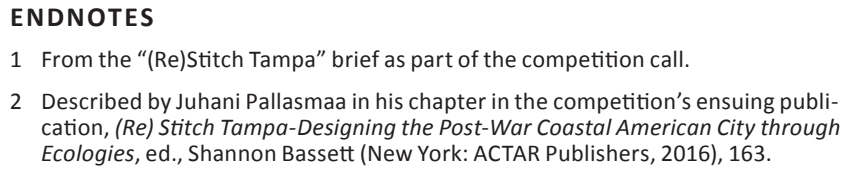

2 Described by Juhani Pallasmaa in his chapter in the competition's ensuing publication, (Re) Stitch Tampa-Designing the Post-War Coastal American City through Ecologies, ed., Shannon Bassett (New York: ACTAR Publishers, 2016), 163. 


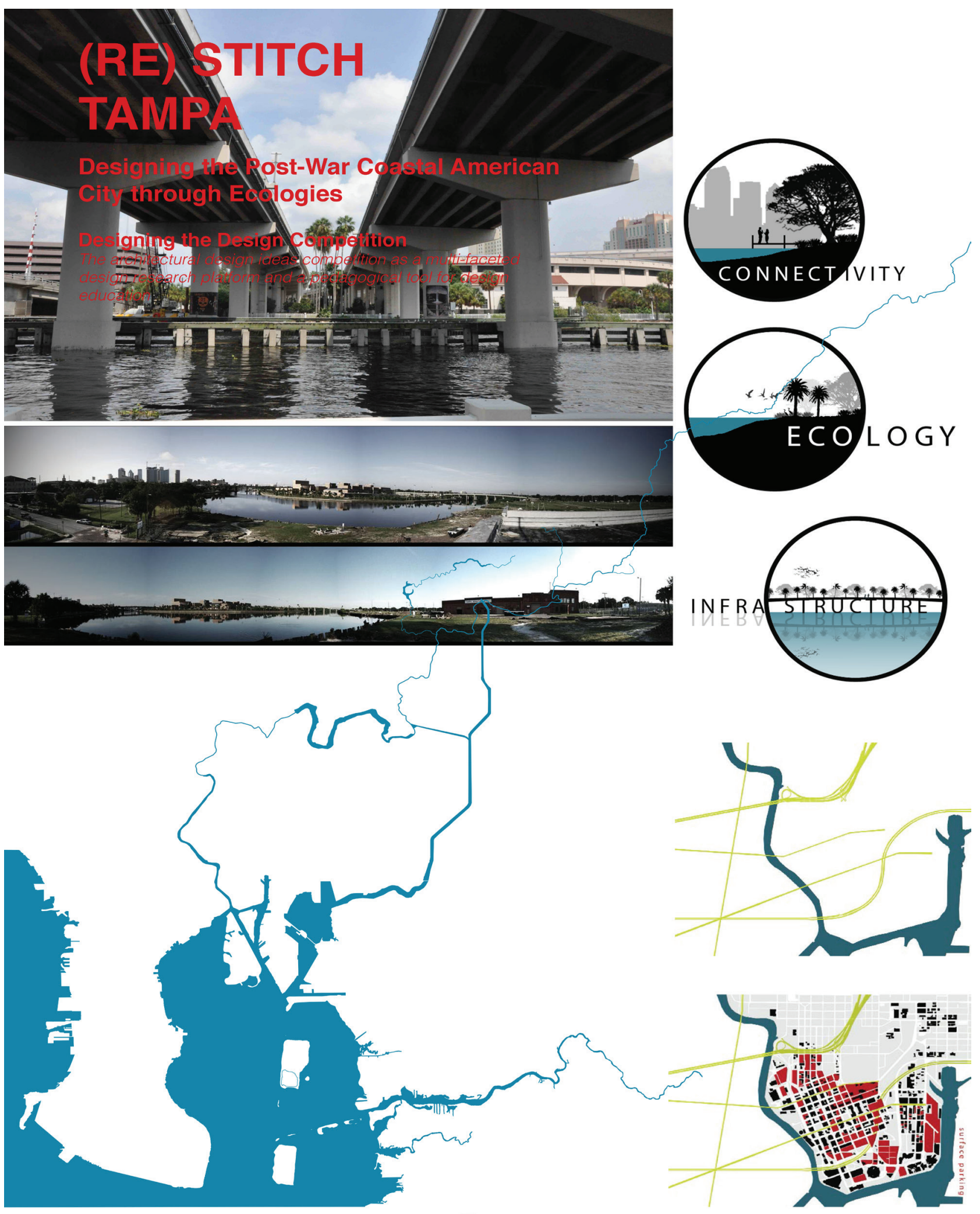

${ }_{n=0}^{2}+x^{2}$

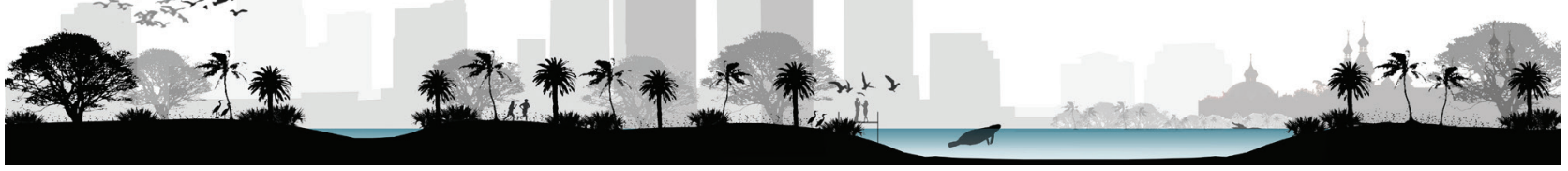

